\title{
On Monotonically T2-spaces and Monotonically normal spaces
}

\author{
Radhi I.M.Ali* \\ Jalal Hatem Hussein*
}

Date of acceptance 22/9/2008

\begin{abstract}
In this paper we show that if $\Pi \mathrm{Xi}$ is monotonically $\mathrm{T} 2$-space then each $\mathrm{Xi}$ is monotonically $\mathrm{T} 2$-space, too. Moreover, we show that if $\Pi \mathrm{Xi}$ is monotonically normal space then each $\mathrm{Xi}$ is monotonically normal space, too. Among these results we give a new proof to show that the monotonically $\mathrm{T} 2$-space property and monotonically normal space property are hereditary property and topologically property and give an example of T2-space but not monotonically T2-space.
\end{abstract}

Keywords: topological space, continuous function, monotonically $T_{2^{-}}$ spaus, monotonically normal space.

\section{Introduction}

The property of monotonically $\mathrm{T} 2$ space first appeared by R.E. Buck, some weaker monotone separation and basis properties are presented in [1]. Unfortunately Buck's definition is not precise so we give a precise definition of monotonically $\mathrm{T} 2$-space and find several properties of such concept and other topological concepts. In order to make this work as self-contained as possible we give the following lemmas.

Lemma 1.1: [6] Let $X, Y$ is two topological spaces and $\mathrm{f}: \mathrm{X} \rightarrow \mathrm{Y}$ is $\quad$ a closed injective function then $\mathrm{f}$ is open function.

Proof: Let $\mathrm{W}$ be any open set in $\mathrm{X}$, $\mathrm{X} \backslash \mathrm{W}$ is closed set. Hence $\mathrm{f}(\mathrm{X} \backslash \mathrm{W})$ is closed set in $\mathrm{Y}$. Since $\mathrm{f}$ is injective $\mathrm{f}$ $(\mathrm{X} \backslash \mathrm{W})=\mathrm{Y} \backslash \mathrm{f}(\mathrm{W})$ which implies that $\mathrm{f}$ (W) is open set in $\mathrm{Y}$. Therefore $\mathrm{f}$ is open function $\square$

Lemma 1.2: [6] Let $X, Y$ is two topological spaces and $\mathrm{f}: \mathrm{X} \rightarrow \mathrm{Y}$ is a continuous closed injective function and let $\mathrm{B}$ be a subset of $\mathrm{Y}$ then
$\mathrm{f}(\mathrm{B})=\mathrm{f}(\mathrm{B})$

Proof: Since $f$ is continuous we have $f$ ${ }^{1}(\mathrm{~B}) \subseteq \mathrm{f}^{1}(\mathrm{~B})$

Let $x \in f(\bar{B})$, i.e. $f(x) \in \bar{B}$. If $W$ is any open set in $\mathrm{X}$ containing $\mathrm{x}$, then $\mathrm{f}(\mathrm{W})$ is open set in $\mathrm{Y}$ containing $\mathrm{f}(\mathrm{x})$ which implies that $\mathrm{f}(\mathrm{W}) \cap \mathrm{B} \neq \varphi$ and have $\mathrm{W} \cap \mathrm{f} \quad(\mathrm{B}) \neq \varphi$, therefore $\mathrm{x} \in \mathrm{f} \quad(\mathrm{B}) \square$

\section{Monotonically T2-space}

Let $(\mathrm{x}, \tau \mathrm{x})$ be a topological space, we begin with precise definition of monotonically $\mathrm{T} 2$-space.

Definition 2.1: Let $\Delta=\{(\mathrm{x}, \mathrm{x}): \mathrm{x} \in \mathrm{X}\}$ and denote by $(\mathrm{X} \times \mathrm{X})^{*}=(\mathrm{X} \times \mathrm{X}) \backslash \Delta$

A topological space $X$ is monotonically $\mathrm{T} 2$-space if there is a function

$\mathrm{g}:(\mathrm{X} \times \mathrm{X})^{*} \rightarrow \tau \mathrm{x}$ 
Assigning to each order pair $(\mathrm{x}, \mathrm{y})$ in $(\mathrm{X}$ $\mathrm{x} \mathrm{X})^{*}$ an open neighborhood $\mathrm{g}(\mathrm{x}, \mathrm{y}) \subset$ $\mathrm{X}$ of $\mathrm{x}$ such that

(i) $\mathrm{g}(\mathrm{x}, \mathrm{y}) \cap \mathrm{g}(\mathrm{y}, \mathrm{x})=\phi$,

(ii) For each subset $\mathrm{M}$ of $\mathrm{X}$ and if

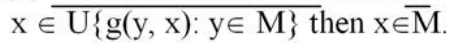

We will call such a function $g$ monotone T2-operator on $\mathrm{X}$. Of course, every monotonically $\mathrm{T} 2$-space is T2-space, but later we find an example of T2-space but not monotonically $\mathrm{T} 2$-space

Theorem 2.2: $\operatorname{If}(\mathrm{X}, \tau \mathrm{x})$ is a topological space, $(\mathrm{Y}, \tau \mathrm{Y})$ is a topological space which is monotonically T2-space and $\mathrm{f}: \mathrm{X} \rightarrow \mathrm{Y}$ continuous closed injective function then $\mathrm{X}$ is a monotonically T2-space.

Proof: Let $\mathrm{g}^{\prime}$ be monotone T2-operator on $\mathrm{Y}$, i.e.

$\mathrm{g}^{\prime}:(\mathrm{Y} \times \mathrm{Y})^{*} \rightarrow \tau \mathrm{Y}$

Satisfies (i) and (ii) of definition (2.1).

In order to define a monotone T2operator on $\mathrm{X}$, let $(\mathrm{x}, \mathrm{y}) \in(\mathrm{X} \mathrm{x} X)^{*}$ then $(\mathrm{f}(\mathrm{x}), \mathrm{f}(\mathrm{y}))$ in $(\mathrm{Y} \times \mathrm{Y})^{*}$ because $\mathrm{f}$ is injective. So there is an open neighborhood $g^{\prime}(f(x), f(y)) \subseteq Y$ of $f(x)$ . Since $\mathrm{f}$ is continuous from $\mathrm{X}$ into $\mathrm{Y}$ $f\left(g^{\prime}(f(x), f(y))\right)$ is an open neighborhood of $x$ subset of $X$.

Define $\mathrm{g}:(\mathrm{X} \times \mathrm{X})^{*} \rightarrow \tau \mathrm{X}$ as follows $\mathrm{g}(\mathrm{x}, \mathrm{y})=\mathrm{f} \quad\left(\mathrm{g}^{\prime}(\mathrm{f}(\mathrm{x}), \mathrm{f}(\mathrm{y}))\right) \quad$ for all $(\mathrm{x} . \mathrm{y}) \in(\mathrm{X} x \mathrm{X})^{*}$.

We note that

$\mathrm{g}(\mathrm{x}, \mathrm{y}) \cap \mathrm{g}(\mathrm{y}, \mathrm{x})=\mathrm{f} \quad\left(\mathrm{g}^{\prime}(\mathrm{f}(\mathrm{x}), \mathrm{f}(\mathrm{y}))\right) \cap \mathrm{f}$ $\left(g^{\prime}(f(y), f(x))\right)$

$=\mathrm{f}(\phi)=\phi$.

$$
=\mathrm{f} \quad\left(\mathrm{g}^{\prime}(\mathrm{f}(\mathrm{x}), \mathrm{f}(\mathrm{y})) \cap \mathrm{g}^{\prime}(\mathrm{f}(\mathrm{y}), \mathrm{f}(\mathrm{x}))\right)
$$

Let $M$ be any subset of $X$ and $x \in U$ $\{\mathrm{g}(\mathrm{y}, \mathrm{x}): \mathrm{y} \in \mathrm{M}\}$ i.e

$\mathrm{x} \in \mathrm{U}\left\{\mathrm{f} \quad\left(\mathrm{g}^{\prime}(\mathrm{f}(\mathrm{y}), \mathrm{f}(\mathrm{x}))\right): \mathrm{y} \in \mathrm{M}\right\}=\mathrm{f}$

$\left(\mathrm{U}\left\{\mathrm{g}^{\prime}(\mathrm{f}(\mathrm{y}), \mathrm{f}(\mathrm{x})): \mathrm{y} \in \mathrm{M}\right\}\right)$

$\therefore \mathrm{x} \in \mathrm{f} \quad\left(\mathrm{U}\left\{\mathrm{g}^{\prime}(\mathrm{f}(\mathrm{y}), \mathrm{f}(\mathrm{x})): \mathrm{y} \in \mathrm{M}\right\}\right)$

which implies that $f(x) \in U\left\{g^{\prime}(f(y), f(x)) \quad: \quad y \in M \quad\right\}$. i.e. $\mathrm{f}(\mathrm{x}) \in \mathrm{U}\left\{\mathrm{g}^{\prime}(\mathrm{f}(\mathrm{y}), \mathrm{f}(\mathrm{x})): \mathrm{f}(\mathrm{y}) \in \mathrm{f}(\mathrm{M})\right\}$.

Hence $f(x) \in f(M)$ because $Y$ is monotonically T-space.

$\therefore \mathrm{f}(\mathrm{x}) \in \mathrm{f}(\mathrm{M})$ because $\mathrm{f}$ is closed function, which implies $\mathrm{x} \in \mathrm{M}$ because is injective function. Thus $\mathrm{X}$ is monotonically $\mathrm{T} 2$-space and $\mathrm{g}$ is monotone $\mathrm{T} 2$-operator on $\mathrm{X} \square$

Corollary 2.3: If topological space $X$ is a homeomorphic to monotonically $\mathrm{T} 2$-space $\mathrm{Y}$ then $\mathrm{X}$ is monotonically T2-space.

Proof: Since a Homeomorphism function is a continuous closed injective function then the result can be deduced from theorem 2.2.

Theorem 2.4 [2]: If the topological space is monotonically $\mathrm{T} 2$-space then $\mathrm{X}$ is regular space.

We are going to give an example of T2-space but not monotonically T2space.

Example 2.5 [6]: Let $X$ denote the closed interval $[0,1]$ and $\mathrm{D}$ the subset $\{1 / n: n=1,2,3 \ldots\}$. Define on $X$ the smallest topology which contains every open set of $X \backslash\{0\}$ as a subspace of the real line $\mathrm{R}$ and every set $\mathrm{Ba},(0<\mathrm{a} \leq 1)$, defined by $\mathrm{Ba}=\{\mathrm{t} \in \mathrm{X}: \mathrm{t}<\mathrm{a}$ and $\mathrm{t} \notin \mathrm{D}\}$. The space $X$ is $T 2$-space but not regular which implies it is not monotonically $\mathrm{T} 2$-space.

Theorem 2.6[2]: If $\mathrm{X}$ is a monotonically $\mathrm{T} 2$-space and $\mathrm{A}$ is a subspace of $\mathrm{X}$ then $\mathrm{A}$ is monotonically T2-space.

In the following theorem we are going to show that if the product

$\mathrm{X} \times \mathrm{Y}$ is monotonically $\mathrm{T} 2$-space then $\mathrm{X}$ and $\mathrm{Y}$ are monotonically $\mathrm{T} 2$-spaces. 
Theorem 2.7: Let $\mathrm{X}, \mathrm{Y}$ be two topological spaces. If the product space $\mathrm{X} x \mathrm{Y}$ is monotonically $\mathrm{T} 2$-space then $\mathrm{X}, \mathrm{Y}$ are monotonically $\mathrm{T} 2$-spaces.

Proof: For each fixed $\mathrm{y} \in \mathrm{Y}, \mathrm{X} \mathrm{x}\{\mathrm{y}\}$ is a subspace of $\mathrm{X} \times \mathrm{Y}$ then by theorem $2.6 \mathrm{Xx}\{\mathrm{y}\}$ is a monotonically $\mathrm{T} 2-$ space but $\mathrm{X} x\{\mathrm{y}\}$ homeomorphic to space $\mathrm{X}$ hence, by corollary $2.3, \mathrm{X}$ is monotonically $\mathrm{T} 2$-space. Using same argument we can show that $\mathrm{Y}$ is monotonically $\mathrm{T} 2$-space, too. $\square$

Use mathematical induction and apply theorem 2.7 we can get the following result $\square$

Corollary 2.8: Let $\mathrm{Xi}$ be indexed family of topological spaces .If the product space $\Pi \mathrm{Xi}$ is monotonically $\mathrm{T} 2$-space then each $\mathrm{Xi}$ is monotonically $\mathrm{T} 2$-space.

\section{Monotonically Normal spaces}

The property of monotone normality first appears without name, in Lemma 2.1 of C.R. Borge's paper on startifiable spaces [3]. In [4], Zenor and others gave properties and characterizations of monotonically normal spaces.

Definition 3.1 A T1-space $\mathrm{X}$ is monotonically normal if there is a function $\mathrm{G}$ which assigns to each order pair $(\mathrm{H}, \mathrm{K})$ of disjoint closed subsets of $X$ an open set $G(H, K)$ such that

(i) $\mathrm{H} \subset \mathrm{G}(\mathrm{H}, \mathrm{K}) \subset \mathrm{G}(\mathrm{H}, \mathrm{K}) \subset \mathrm{X} \backslash \mathrm{K}$

(ii) If $\left(\mathrm{H}^{\prime}, \mathrm{K}^{\prime}\right)$ is a pair of disjoint closed subsets of $\mathrm{X}$ such that $\mathrm{H} \subset \mathrm{H}^{\prime}$ and $\mathrm{K} \supset$ $\mathrm{K}^{\prime}$, then $\mathrm{G}(\mathrm{H}, \mathrm{K}) \subset \mathrm{G}\left(\mathrm{H}^{\prime}, \mathrm{K}^{\prime}\right)$.

The function $\mathrm{G}$ is called a monotone normality operator for $\mathrm{X}$.

Lemma 3.2: [4] Any monotonically normal has a monotone normality operator $G$ satisfying $\mathrm{G}(\mathrm{H}, \mathrm{K}) \cap$ $\mathrm{G}(\mathrm{K}, \mathrm{H})=\phi$ for any pair $(\mathrm{H}, \mathrm{K})$ of closed sets. Furthermore, each of the following properties is equivalent to monotone normality of a space $\mathrm{X}$ :

(a) There is a function $G$ which assigns to each order pair $(\mathrm{S}, \mathrm{T})$ of separated subsets of $X$ an open set $G(S, T)$ satisfying

(i) $\mathrm{S} \subset \mathrm{G}$ (S, T) $\subset \mathrm{G}$ (S, T) $\subset \mathrm{X} \backslash \mathrm{T}$.

(ii) If $\left(S^{\prime}, T^{\prime}\right)$ is a pair of separated sets having $S \subset S^{\prime}$ and $T \supset T^{\prime}$ then $G(S, T)$ $\subset \mathrm{G}\left(\mathrm{S}^{\prime}, \mathrm{T}^{\prime}\right)$.

(b) There is a function $F$ which assigns to each order pair (p, C)

with $\mathrm{C}$ closed set and $\mathrm{p} \in \mathrm{X} \backslash \mathrm{C}$, an open set $F(p, C)$

satisfying

(i) $\mathrm{p} \in \mathrm{F}(\mathrm{p}, \mathrm{C}) \subset \mathrm{X} \backslash \mathrm{C}$

(ii) If $\mathrm{D}$ is closed and $\mathrm{C} \supset \mathrm{D}$ then $\mathrm{F}$ ( $\mathrm{p}$, C) $\subset \mathrm{F}(\mathrm{p}, \mathrm{D})$.

(iii)If $\mathrm{p} \neq \mathrm{q}$ are points of $\mathrm{X}$ then $\mathrm{F}$ ( $\mathrm{p}$, $\{\mathrm{q}\}) \cap \mathrm{F}(\mathrm{q},\{\mathrm{p}\})=\phi$.

Remarks 3.3: [4] (a) The property described in lemma 3.2 (a) was originally called complete monotone normality and because condition (i) in (a) the space is T5-space. Hence the space which is normal but it is not T5space is a normal space but not monotonically normal space, see [5].

Theorem 3.4: If $X$ is monotonically normal and $\mathrm{A}$ is a closed subspace of $\mathrm{X}$ then $\mathrm{A}$ is monotonically normal space, too.

Proof : Let $\mathrm{G}$ be a monotone normality operator for $\mathrm{X}$ and $\mathrm{H} 1, \mathrm{~K} 1$ be any two disjoint closed sets in $\mathrm{A}$, so $\mathrm{H}=\mathrm{Hl} \cap$ $\mathrm{A}, \mathrm{K}=\mathrm{K} 1 \cap \mathrm{A}$ are two disjoint closed sets in $\mathrm{X}$.Hence there is an open set $\mathrm{G}(\mathrm{H}, \mathrm{K})$ in $\mathrm{X}$, we can define a function $\mathrm{G} 1$ assigns to each order pair $(\mathrm{H} 1, \mathrm{~K} 1)$ an open set $\mathrm{G} 1(\mathrm{H} 1, \mathrm{~K} 1)$ in A such that $\mathrm{Gl}(\mathrm{H} 1, \mathrm{~K} 1)=\mathrm{G}(\mathrm{H}, \mathrm{K}) \cap \mathrm{A}$, It is easy to show that Gl is a monotone normality operator for $\mathrm{A} \square$

Theorem 3.5: If $(X, \tau x)$ is a topological space, $(\mathrm{Y}, \tau \mathrm{Y})$ is a 
monotone normal space with $G$ is a monotone normality operator for $\mathrm{Y}$ and $\mathrm{f}: \mathrm{X} \rightarrow \mathrm{Y}$ continuous closed injective function then $\mathrm{X}$ is a monotonically normal space, too.

Proof: Let $\mathrm{H}, \mathrm{K}$ be any two disjoint closed sets in $\mathrm{X}$. Since $\mathrm{f}$ is closed and injective function, $\mathrm{f}(\mathrm{H}), \mathrm{f}(\mathrm{K})$ are two disjoint closed sets in $\mathrm{Y}$ and hence there is an open set $G(f(H), f(K))$ in $Y$ assigns with $(\mathrm{f}(\mathrm{H}), \mathrm{f}(\mathrm{K})) . \mathrm{f}$ $(\mathrm{G}(\mathrm{f}(\mathrm{H}), \mathrm{f}(\mathrm{K})))$ is an open set in $\mathrm{X}$ therefore we can define a function $\mathrm{G}^{\prime}$ assigns with $H, K$ an open set $G^{\prime}(H, K)$ in $\mathrm{X}$ as follows

$\mathrm{G}^{\prime}(\mathrm{H}, \mathrm{K})=\mathrm{f}(\mathrm{G}(\mathrm{f}(\mathrm{H}), \mathrm{f}(\mathrm{K})))$

Since $G$ is a monotone normality operator in $\mathrm{Y}$ and $\mathrm{f}$ is closed we obtain from

$$
\mathrm{f}(\mathrm{H}) \subset \mathrm{G}(\mathrm{f}(\mathrm{H}), \mathrm{f}(\mathrm{K})) \subset \mathrm{G}
$$

$(\mathrm{f}(\mathrm{H}), \mathrm{f}(\mathrm{K})) \subset \mathrm{Y} \backslash \mathrm{f}(\mathrm{K})$,

$\mathrm{H} \subset \mathrm{f} \quad(\mathrm{G}(\mathrm{f}(\mathrm{H}), \mathrm{f}(\mathrm{K}))) \subset \mathrm{f}$

$(\mathrm{G}(\mathrm{f}(\mathrm{H}), \mathrm{f}(\mathrm{K})))=\mathrm{f} \quad(\mathrm{G}(\mathrm{f}(\mathrm{H}), \mathrm{f}(\mathrm{K})))$

$\subset \mathrm{f}(\mathrm{Y} \backslash \mathrm{f}(\mathrm{K}))=\mathrm{X} \backslash \mathrm{K}$

Moreover, let $\left(\mathrm{H}^{\prime}, \mathrm{K}^{\prime}\right)$ be a pair of disjoint closed sets in $\mathrm{X}$ having

$\mathrm{H} \subset \mathrm{H}^{\prime}$ and $\mathrm{K} \supset \mathrm{K}^{\prime}$. Since $\mathrm{f}$ is closed and injective function we have $\mathrm{f}(\mathrm{H}) \subset$ $\mathrm{f}\left(\mathrm{H}^{\prime}\right)$ and $\mathrm{f}(\mathrm{K}) \supset \mathrm{f}\left(\mathrm{K}^{\prime}\right)$. Hence $\mathrm{G}(\mathrm{f}(\mathrm{H})$ $, f(K)) \subset G\left(f\left(H^{\prime}\right) . f\left(K^{\prime}\right)\right)$ implies $f$ $(\mathrm{G}(\mathrm{f}(\mathrm{H}), \mathrm{f}(\mathrm{K}))) \subset \mathrm{f} \quad\left(\mathrm{G}\left(\mathrm{f}\left(\mathrm{H}^{\prime}\right), \mathrm{f}\left(\mathrm{K}^{\prime}\right)\right)\right)$ i.e. $\mathrm{G}^{\prime}(\mathrm{H}, \mathrm{K}) \subset \mathrm{G}^{\prime}\left(\mathrm{H}^{\prime}, \mathrm{K}^{\prime}\right)$

$\therefore \mathrm{G}^{\prime}$ is a monotone normality operator for $\mathrm{X} \square$

Corollary 3.6: The monotonically normal property of space is topological property.

Proof: Homeomorphism is continuous closed injective function and use theorem $3.5 \square$

In the following theorem we are going to show that if the product space $\mathrm{X} \times \mathrm{Y}$ is a monotonically normal space then $\mathrm{X}, \mathrm{Y}$ are monotonically normal spaces.
Theorem 3.7: let $\mathrm{X}$ and $\mathrm{Y}$ be two topological spaces. If the product space $\mathrm{X} x \mathrm{Y}$ is monotonically normal space then $\mathrm{X}, \mathrm{Y}$ are monotonically normal spaces.

Proof: For each fixed $y \in Y, X x\{y\}$ is closed subspace of $\mathrm{X} \times \mathrm{Y}$ and then by theorem $3.4 \times \quad x \quad\{y\}$ is monotonically normal space But $\mathrm{X} x$ $\{\mathrm{y}\}$ homeomorphic to space $\mathrm{X}$ hence $\mathrm{X}$ is monotonically normal space. By using same argument we can show that $\mathrm{Y}$ is monotonically normal space $\square$

Use mathematical induction and apply theorem 3.7 we can get the following result.

Corollary 3.8: Let Xi indexed family of topological spaces .If the product space $\Pi \mathrm{Xi}$ is monotonically normal space then $\mathrm{Xi}$ is monotonically normal space.

\section{References:}

1. Buck, R.E., 1996 Some weaker monotone separation and basis properties, Topology and its Applications. 69:1-12.

2. Buck, R.E., 1993 Monotone separation and basis properties, Ph.D. Thesis, University of Pittsburgh, Pittsburgh, PA.

3. Borges, C.J.R., 1966 On startifiable spaces, Pacific J.Math. 17:1-16.

4. Heath ,R.W., Lutzer D.J. and Zenor P.L., 1973 Monotonically normal spaces, Trans, Amer, Math. Soc. 178: 481-493.

5. Shkerin ,S.A. 2004. Topology and its Applications.136:129134.

6. Steen, L. A. and Seebach J. A. Jr., 1970. Counterexamples in Topology. Holt, Rinehart and 
Winston, Inc., New York, $210 \mathrm{pp}$

7. Hu, S.T., 1969 Element of general topology, 3rd Ed,
Holaen. Day, Inc, California, $214 \mathrm{pp}$

\section{الفضاءات T2 الرتيبية و الفضاءات العادية الرنتيبية}

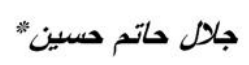

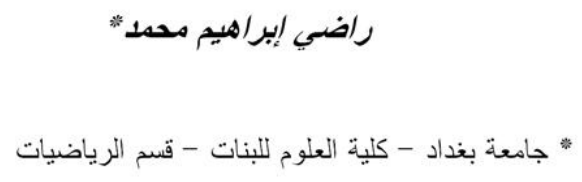

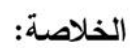

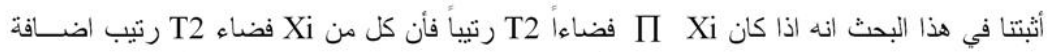

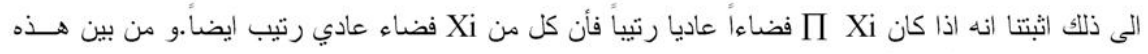

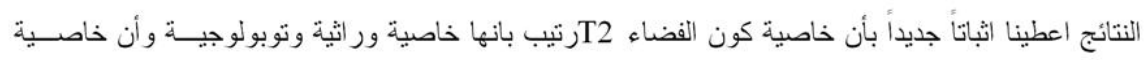

كون الفضاء الرتيب العادي خاصية ور اثية وتوبولوجية واعطينا مثالاً لفضاء T2 لكنه ليس فضاء النياء 